\title{
Life Cycle Management for Main Transformers at Nuclear Power Plants
}

\author{
C. F. YANG \\ System Engineering Centre, Suzhou Nuclear Power Research Institute, Suzhou, China
}

\begin{abstract}
In order to ensure reliability and safety of nuclear power plants remain within acceptable limits and to achieve cost-effective investment, based on technical and economic analysis method, a economic analysis model of life cycle management (LCM) for main transformers at nuclear power plants is established. As an example, the 60-year alternative LCM plans for a main transformer at a nuclear power plant in China are given. According to the proposed economic analysis model and various economic data input, the preventive maintenance costs, corrective maintenance costs, lost production costs, net present value of total benefit and total investment for the LCM alternatives are output, and ultimately the net present value index is calculated to determine the advantages and disadvantages of various alternatives and identify the best economic LCM alternative. The results provide basis for decision making for the major equipments LCM and life extension plans in nuclear power plants.
\end{abstract}

KEYWORD: Life cycle management; Economy analysis model; Net present value; Preventive maintenance; Corrective maintenance; Nuclear power plants.

\section{INTRODUCTION}

Life Cycle Management (LCM) planning is intended to provide an effective long-term planning tool for minimizing unplanned capability loss and optimizing maintenance programs and capital investments consistent with plant safety and an identified plant operating strategy [1]. Such an operating strategy might include license renewal or retaining the option for license renewal. An LCM Plan addresses such issues as aging management, preventive maintenance, technical obsolescence, and the replacement or redesign of a system, structure, or component (SSC) important to safety and plant operation. In short, LCM Planning is viewed as a viable process to systematically identify and examine the important SSCs, optimize their contribution to plant performance, reliability, safety and value, and prepare long-term maintenance management plans and resource projections [2].

The objective of the economic evaluation for SSC LCM alternatives at nuclear power plants is to select the optimal LCM alternative plan and to enable SSCs to maintain safe, reliable, economic operation to the end of lifetime [3-4].

This paper presents a LCM economic evaluation model for SSCs, and the LCM for main transformer of a domestic nuclear power plant is selected as an example, and the economic evaluation model proposed are adopted to evaluate the LCM alternative plans for main transformers and select the best LCM plan on the premise of not reducing safety and reliability of nuclear power plants, to promote main transformer to operate to the end of lifetime of nuclear power plants, to bring the maximum economic benefits for nuclear power plants, and to provide support for funds reservation plan of plants[5-9].

\section{ALTERNATIVE LCM PLANS}

All main transformer components are nominally designed for 30-year life. However, this relates more to the traditional period of amortization rather than to technical design life. There is an expectation that the transformer will be designed and manufactured so that it will operate at average transformer reliability for a period of 30 years, under normal operating conditions, without the need for any major component replacements or upgrades. This period has been extended to 40 years or 60 years by most users.

The LCM planning alternatives were determined on the basis of current reliability performance of main transformer. 
For the purpose of LCM Plan the following maintenance strategy, plant strategy of operating the plant for its currently licensed period of 60 years, have been selected for comparison of their cost streams over the plant life.

According to 60-year or 40-year of operation requirement of nuclear power plant, the 60 -year and 40-year LCM alternatives for main transformer are formulated respectively.

Five 60-year LCM alternatives for No.1 main transformer are as follows:

i) Alternative 1A: base case: to maintain the existing strategy unchanged.

ii) Alternative 1B: single-phase transformer replacement.

iii) Alternative 1C: the overall replacement.

iv) Alternative 1D: three phase transformer replacement for power promotion (in 20 years).

v) Alternative 1E: three phase transformer replacement for power promotion (in 30 years).

\section{ECONOMIC EVALUATION METHOD}

Based on the proposed LCM economic evaluation model, a life economic analysis platform software for nuclear power plants is developed and established to do the LCM economic evaluation. The life economic analysis platform evaluate the LCM alternatives from two aspects:

i) Net Present Value (NPV).

Required future costs of SSCs management in nuclear power plant residual life period are obtained by the NPV calculation method commonly used. NPV refers to the net cash flow of alternatives each year during the service life, and it equals the discounted total sum based on the present value at the beginning according to a certain discount rate, and equals the total funds sum invested to pay for the estimated expenses. It is now a evaluation and selection method generally accepted.

By the evaluation of the NPV for each alternative, the total estimated expenses paid for each alternative during whole life period. This is an important index for the investment evaluation of alternatives.

ii) Benefit/investment ratio (B/I Ratio) evaluation.

Through comparing the corrective maintenance (CM) costs, lost production costs, preventive maintenance $(\mathrm{PM})$ costs of the reference alternatives with the ones of the base case alternative, the $\mathrm{B} / \mathrm{I}$ ratio of the reference alternatives and the base case alternative can be calculated out. The $\mathrm{B} / \mathrm{I}$ ratio can reflect the investment profit ability, and determine whether to obtain more investment income of different alternatives by comparing with the base case alternative.

\section{TRANSFORMER FAILURE RATES AND ECONOMIC ANALYSIS MODEL}

\subsection{Failure rates of transformers}

The transformer failure rate was calculated from $X$ forced failure states on $\mathrm{Y}$ transformers over $\mathrm{Z}$ year operating period, distributed over A operating nuclear units. The failure states include forced outages (FO), forced extensions to planned outages, or refueling outages (FEPO) and forced power deratings (FD), converted to equivalent forced outage days.

Component failure rate can be calculated as follow:

$$
F / R=\frac{N_{\text {fail }}}{N_{G} \times T_{o}}
$$

where $F / R=$ the transformer component failure rate; $N_{\text {fail }}=$ failure event number of transformer component; $N_{G}=$ transformer component number; $T_{o}=$ transformer component operating period years.

\subsection{Economic analysis model for LCM}

The economic indicators evaluating transformer replacement alternatives is the net present value index (NPVI), which is the ratio of the total benefit NPV and the total investment NPV. The total benefit NPV equals the sum of the CM cost difference and the loss production cost difference of the alternative plan and the current maintenance plan, and the total investment NPV equals the PM cost difference of the alternative plan and the current maintenance plan. That is,

$$
N P V I=\frac{\Delta \sum \mathrm{NPV}_{C M}+\Delta \sum \mathrm{NPV}_{L P}}{\Delta \sum \mathrm{NPV}_{P M}}
$$

where $\Delta \Sigma \mathrm{NPV}_{C M}=$ the present value of corrective maintenance cost difference; $\Delta \Sigma N P V_{L P}=$ the present value of loss production cost difference; $\triangle \Sigma N P V_{P M}$ $=$ the present value of preventive maintenance cost difference.

PM calculation for the economy analysis model, as one of the three major costs, PM, CM and lost production, is given as a example and as follows:

i) If there is no annual outage maintenance plan, then yearly PM only consists of ongoing PM, then

$$
C_{P M}=C_{M 1}+C_{S 1}+C_{O 1}+\sum_{i} C_{i} \times T_{i}
$$

where $C_{P M}=$ the ongoing maintenance costs; $C_{M 1}=$ the yearly material costs of daily operation and maintenance; $C_{S 1}=$ the subtracts costs of daily maintenance; $C_{O 1}=$ the costs of daily operation and maintenance in other years; $C_{i}=$ the costs of the class $i$ staff for daily operation and maintenance in 
unit time; $T_{i}=$ the total work time of the class $i$ staff for daily operation or maintenance.

ii) If there is outage plan, then yearly PM includes daily PM, outage PM and the refurbishment \& replacement costs of each alternative outage plan. So

$$
\begin{aligned}
C_{P M}=C_{M 1}+C_{S 1}+C_{O 1}+\sum_{i} C_{1 i} \times T_{1 i}+ \\
C_{M 2}+C_{S 2}+C_{O 2}+\sum_{i} C_{2 i} \times T_{2 i}+C_{S P M}
\end{aligned}
$$

where $C_{P M}=$ the outage maintenance costs; $C_{M 2}=$ the material costs of yearly outage maintenance; $C_{S 2}=$ the subtracts costs of yearly outage maintenance; $C_{O 2}=$ the costs of outage maintenance in other years; $C_{2 i}=$ the costs of the class $i$ staff in unit time; $T_{2 i}=$ the work time of the class $i$ staff for yearly outage maintenance; $C_{S P M}=$ the specially optimized maintenance projects of yearly outage maintenance.

On the calculation of NPV, the annual PM is selected as a example to indicate how to convert into the NPV of the base year, and the formula is

$$
N P V_{P M}=\sum_{j_{\text {Fist }}}^{j_{\text {Last }}} C_{j P M}\left[1+i_{0}\right]^{-\left(t_{j}-t_{N P V}\right)}
$$

where $N P V_{P M}=$ the sum of the annual PM calculated values converted into the NPV of the base year; $C_{j P M}$ $=$ the yearly PM calculation value; $j_{\text {First }}=$ the first year of start conversion; $j_{\text {Last }}=$ the last year of finishing conversion; $i_{0}=$ the discount rate; $t_{j}=$ the year of conversion; $t_{N P V}=$ the base year of conversion.

\subsection{Economic analysis model input data}

Some basic economic data needed for the study are given in Table 1.

Table 1. Basic economic data

\begin{tabular}{|l|l|}
\hline Basic economic data & Value \\
\hline Discount rate & $9.08 \%$ \\
\hline Inflation rate & $5.04 \%$ \\
\hline Value-added factor & $5 \%$ \\
\hline Electricity price (¥) & 0.42 \\
\hline
\end{tabular}

The economic analysis tool outputs are based on the following inputs:

i) The financial data inputs, such as inflation and discount rates, lost production costs and labor rates, were obtained from the plant financial section. The data of Ongoing Yearly Costs and Outage Costs were derived from work order reports for PM and $\mathrm{CM}$ activities over the past several years and from external contract costs.

ii) The Failure Modes examine failure probabilities of several major transformer components. The failure rates are based on comparisons with the industry data and estimates of machine specific design features and their effect on expected future failure probabilities. The estimated failure rates change from period to period in each alternative depending on implemented maintenance actions.

\section{ECONOMIC COMPARISON OF LCM ALTERNATIVES}

According to the economic analysis model and the economy input data, the PM cost, CM cost, lost production cost and their NPV of each year for each alternative plan in plant life period (1994 2054 years) can be calculated, which are shown in Table 2 and Figure 1-Figure 5. Table 2 compares the total NPV costs and benefit to investment ratios for each of the analyzed cases. Figure 6 gives the comparison of the NPV of the total PM costs, CM costs and loss production costs for each alternative LCM plan.

The study concludes that, in general, the plant has carried out sound industry practices in maintaining the transformer. This is based on a review of: 1) Plant maintenance practices in terms of both preventive maintenance scope and frequency; 2) Proper system operation with no record of extreme system operating or fault events.

As can be seen from Figure 6 and Table 2, for plant strategy of operating the plant to the end of its 60 -year license, Alternative $1 \mathrm{E}$ is recommended because it results in the highest benefit/investment ratio (8.79) and the lower NPV cost.

Table 2. LCM alternatives total NPV Costs and B/I ratios.

\begin{tabular}{|c|c|c|c|c|}
\hline $\begin{array}{c}\text { LCM } \\
\text { PLAN } \\
\text { alternatives }\end{array}$ & $\begin{array}{c}\text { PM } \\
\text { costs } \\
(\mathrm{k} ¥)\end{array}$ & $\begin{array}{c}\text { CM } \\
\text { costs } \\
(\mathrm{k} ¥)\end{array}$ & $\begin{array}{c}\text { Lost } \\
\text { production } \\
\text { costs (k¥) }\end{array}$ & $\begin{array}{c}\text { B/I } \\
\text { ratios/NPVI }\end{array}$ \\
\hline 1A & 49966 & 33472 & 664002 & N/A \\
\hline 1B & 110074 & 16471 & 328424 & 5.87 \\
\hline 1C & 111828 & 17296 & 344799 & 5.42 \\
\hline 1D & 1811845 & 13838 & 284737 & 5.95 \\
\hline 1E & 122003 & 17296 & 353938 & 8.79 \\
\hline
\end{tabular}

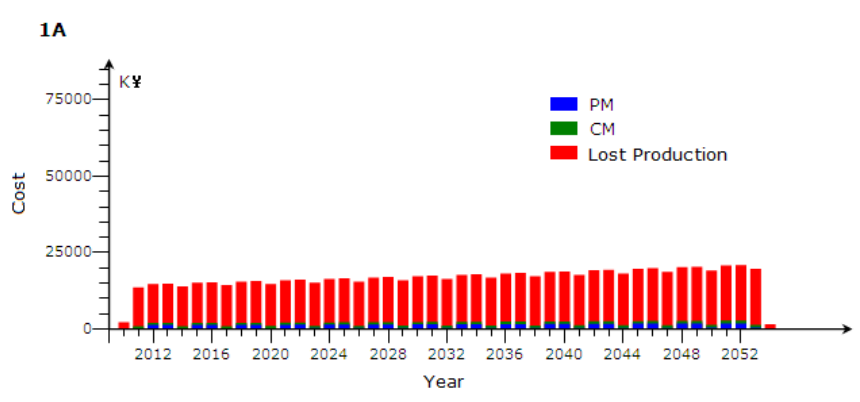

Figure 1. Nominal yearly costs of alternative 1A. 


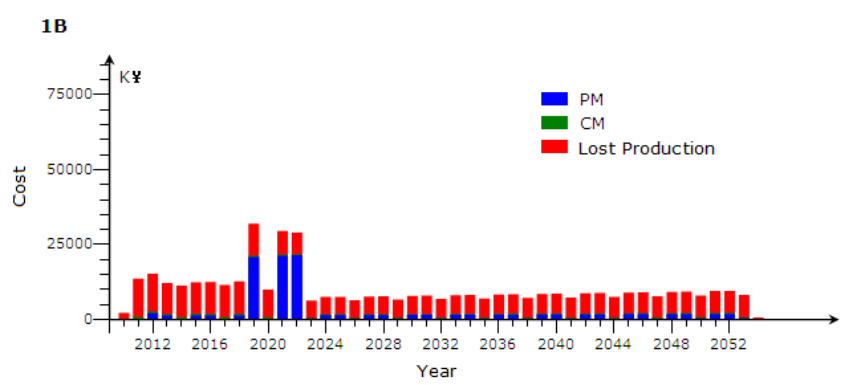

Figure 2. Nominal yearly costs of alternative 1B.

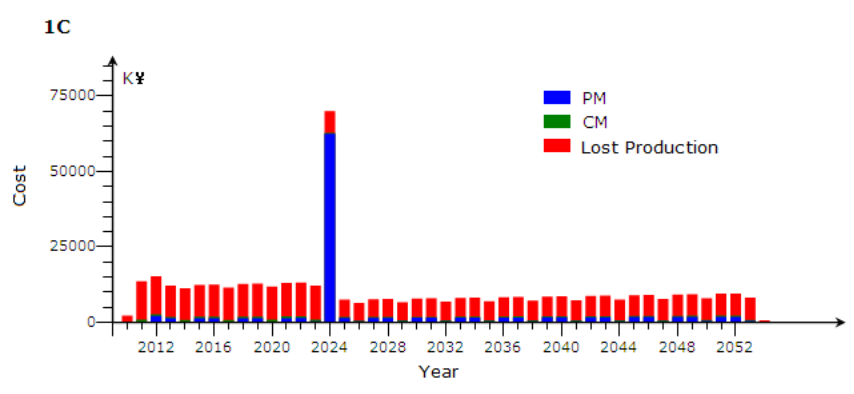

Figure 3. Nominal yearly costs of alternative $1 \mathrm{C}$.

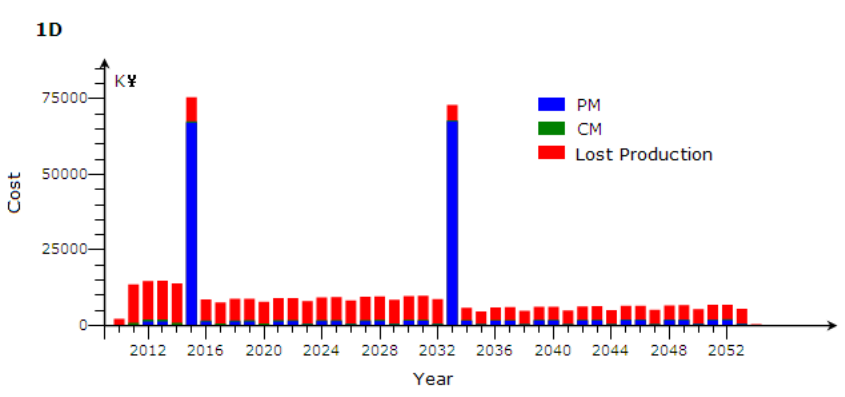

Figure 4. Nominal yearly costs of alternative 1D.

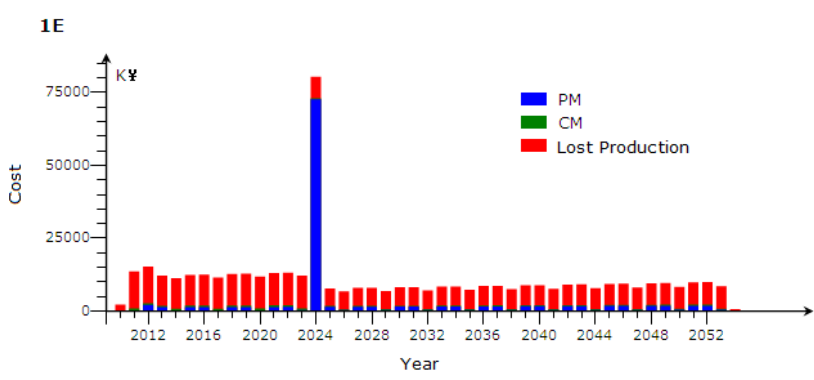

Figure 5. Nominal yearly costs of alternative $1 \mathrm{E}$.

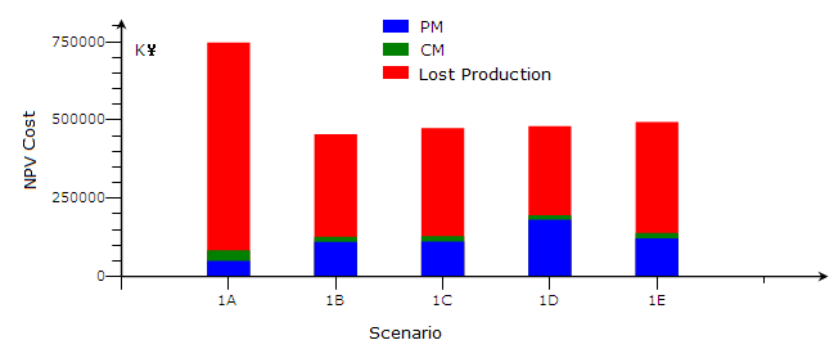

Figure 6. Nominal net present value costs.

\section{CONCLUSIONS}

Life cycle management is important for the relevant decision-making process optimization for the SSCs operation lifetime to improve the availability of SSCs, and to maximize the value and the long-term benefit of the lifetime of nuclear power plants. In order to ensure reliability and safety of nuclear power plants remain within acceptable limits and to achieve cost-effective investment in nuclear power plants, based on technical and economic analysis method, a LCM economic analysis model for the SSCs at nuclear power plants is established. A main transformer of a nuclear power plant in operation is made as an example, the 60-year LCM alternatives for the main transformer are given. According to the proposed economic analysis model and various economic data input, the preventive maintenance costs, corrective maintenance costs and loss production costs for the LCM alternatives during the plant service life, the alternatives net present value of total benefit and total investment are output, and ultimately the net present value index is calculated to determine the advantages and disadvantages of various alternatives and identify the best economic LCM alternative. The analysis results based on the economy model are introduced to provide basis for decision making for the major equipments LCM and life extension plans in nuclear power plants.

\section{ACKNOWLEDGEMENTS}

The research work was supported by the Major Strategic Project Funds from China General Nuclear Power Corporation.

\section{REFERENCES}

[1] EPRI, Nuclear Plant Life Cycle Management Implementation Guide, 1998.

[2] EPRI, Life Cycle Management Planning Sourcebooks-Overview Report, 2001.

[3] EPRI, Life Cycle Management Planning Sourcebook Volume 4: large Power Transformers, 2003.

[4] EPRI, Transformer operating risk assessment: Development of models, 2005.

[5] IAEA, IAEA-TECDOC-1305 Safe and effective nuclear power plant life cycle management towards decommissioning, 2002.

[6] IAEA, IAEA-technical repores series No338 Methodology for Ageing Management of NPP Components Important to Safety, 1992.

[7] IAEA, Safety Reports Series No.15 Implementation and Review of Nuclear Power Plant Aging Management Program, 1999.

[8] M. Bruning. Absolute vs. comparative end-of-life age. IEEE Transactions on Dielectrics and Electrical Insulation, 1996, 3(4): 567-576.

[9] K. Matsuura. Life expectancy oriented insulation diagnosis. Proceedings of 96 'AICDEI \& 4th JCCEID, 1996: 303-314. 